\title{
Focus on Finance: Aiming for Restaurant Success
}

\author{
Alex M. Susskind and Rupert Spies
}

We all know that the most important thing about a restaurant-the thing that stands out and shapes a guest's experience-is the food. Not only that, but we can name other elements that are crucial to the guest's restaurant experience, including staff, service, location, ambience and decor, menu, and overall execution. But restaurants can survive weaknesses in all those areas and still remain in business. We've all seen those places. What a restaurant cannot survive is failure of financial management, including focusing on revenue, profit, expenses, debt, and appropriate staffing levels. It's true that restaurants fail due to market factors or even due to a lack of expertise, ${ }^{1}$ but as we see it, the financial side of the restaurant business doesn't get the attention it deserves. For this reason, in this chapter we explain the specific connection between the elements of food-service management and the income statement and balance sheet. Our goal is to focus on restaurant success factors by discussing these two important documents, and the many operational elements that go into them. Let's start with the income statement.

\section{Income Statement}

The income statement is a periodic measurement of your business's performance and provides you with important information about four main constituents of any food-service business, namely, the guests, employees, management, and ownership. Most income statements are processed and reported monthly, but, depending on their business cycle, some operators use a 28-day period to provide an equal distribution of days across the year. If you own a franchise, the format will probably be specified by your franchisor; otherwise, you should use a format that meets your operation's needs and provides sufficient operational performance data to assist you in running the business.

Most balance sheets start with the Uniform Systems of Accounts for Restaurants (USAR), published by the National Restaurant Association, which details the basics of financial statements, how they are structured, and how line items are annotated and interpreted. ${ }^{2}$ The format and definitions in the USAR are universally accepted and are used industry-wide. While you're really required only to 
report finances according to the laws set forth by various levels of government, the USAR can provide great guidance on how you can structure and report your financial statements.

Following is an introduction and description of how each line item on the income statement relates to guests, employees, management, and ownership.

Sales

The top line of your income statement is sales or revenue, the money you collect from your guests for the food and beverage you serve, and this is essentially all you have to support the operation of your business. You probably want to break down your sales on a per-guest or per-cover basis. A simple average makes a good starting point. If you record \$1 million of sales in a quarter with 50,000 guests, your average check (or cover) would be $\$ 20$. You probably would want to be more precise, though, and calculate your average check per daypart, for example, or for the drive-through or take-out business. This calculation will give you an idea of your guests' spending behavior in each meal period, and you can get a sense of your guests and the market you serve. It can also help you gauge your performance relative to your competition. Knowing what guests are spending in your competitors' restaurants will help you understand where revenue enhancement opportunities lie.

Breaking down that $\$ 20$ average check even further, you can determine what percentage of your sales comes from food sales and what is from beverage sales. Casual dining restaurants typically record around 12 to 15 percent of sales from beverage alcohol. So, if you are in the casual dining segment and only have 10 percent of sales attributed to alcohol, you might wish to investigate further. Perhaps you have an area for improvement, or it may tell you something about your guests. You might want to focus on how alcoholic beverages enhance your guests' overall meal experience, and put that in the context of how all beverages relate to the meal. You typically would record nonalcoholic beverage sales under the food category (for sales and the cost of goods sold), but you still need to pay attention to the role that nonalcoholic beverages play in the experience for your guests, even more so than alcohol. Together, all these beverages enhance your guests' experience with their meal and offer you the chance to boost check averages.

For this purpose, your service staff should understand how the food and beverage offerings work together. You can train your staff, without being pushy, to help guests select food and beverage products that pair well together and enhance your average check. Many higher-end restaurants, for instance, maintain well-designed programs that allow guests to choose a bottled water to go along with their meal. This supplants tap water, which has zero revenue and 100 percent cost. Additionally, you can 
train your servers to suggest cocktails and other beverages, often as specials, before your guests order their food. Likewise, at the end of the meal, you can set up options for coffee, coffee drinks, and other dessert beverages. When properly marketed and offered by service staff, these additional items simultaneously enhance the average check and the guests' experience. Once again, you do have to use caution in upselling to ensure that your guests are receptive to these products and do not feel pressured or pestered.

All types of restaurants use upselling, of course, just as hoteliers do at the front desk and airlines when you check in. Truthfully, you wouldn't be doing your job if you didn't give your guests the opportunity to increase their pleasure. Our point is that value meals, "super sizes," and the famous "would you like some fries with that" are all elements that allow operators to boost their guests' spending, but they also deliver notable add-on value. If you know what your guests are purchasing and why, you can identify ways to enhance your average check, while creating a positive experience for your guests.

Forecasting: To ensure that you can meet your guests' demands, you need to be able to forecast those demands. For existing operators, forecasting involves a close examination of historical data and an analysis of market factors - such as market trends, competition, and sociodemographics. All of this should help you uncover guests' behavior and preferences. New businesses that don't have solid historical data can forecast based on an analysis of market trends, competition in the marketplace, and an examination of market demographics and predicted consumption patterns.

Forecasting requires meticulous collection and analysis of data that will allow you to accurately predict how many guests might frequent the restaurant, what food and beverage they will choose (menu mix), and, as a consequence, what ingredients you will need to order and how many staff members you'll need to hire and schedule.

\section{Cost of Sales}

Although sales levels are important, you also need to take into account the costs of the products you sell, because your net revenue is what's left after you pay the bills. The best pricing, forecasting, and revenue management strategies will fall flat if costs are not managed appropriately.

Restaurant guests are generally price sensitive, so you have to manage costs carefully to keep your prices as reasonable as possible. The fact that restaurant guests pay for the meal after it has been consumed makes price maneuvering more difficult for restaurant operators. 
Three key factors influence an operator's cost of goods: (1) supply chain management (i.e., purchasing, procurement, receiving, storage), (2) recipe management, and (3) product execution.

Supply Chain Management: Supply chain management is a set of complex, interrelated tasks that allow operators to select, procure, purchase, receive, store, and issue the products that are needed to serve their guests. Selection is defined as choosing among alternative forms and preparations of a particular food item. Procurement is the orderly systematic exchange between a seller (or supplier) and a buyer. Procurement involves locating a supplier and determining purchase amounts, purchase sizes, timing, and quality assurance to ensure adequate food supplies. Selection and procurement should be built on requisite product knowledge, including a clear understanding of product quality, standards of identity, and any regulations (e.g., health and legal) that govern the sale and use of these products.

Before you can begin the selection and procurement process, you need a clear understanding of the products you serve and the precise specifications for those products. Some products are easier to "spec" than others, but it is important to identify how the product will be used.

A product specification comprises the following seven elements that need to be considered in concert to ensure that the products you require can be secured for your operation. ${ }^{3}$

1. The spec should offer an accurate quality description. Quality distinctions influence cost, selling price, preparation, storage, and guest perceptions.

2. The spec should have observable features, such as how the food item appears and how it is packed.

3. The spec should be realistic and practical, to ensure that the products and product features fit into your operation, including storage, preparation, and guest demand.

4. The spec should be clear, simple, and direct. The specification is a communication among you, your staff, your suppliers, and your guests. Specs must be aligned with all four.

5. The spec should be based on readily available products that take into account market supply and demand. Although you can get fresh berries year round, you might get different (and inappropriate) quality some $H$ times of the year, or the price may be too high for your concept.

6. The products specified should be available from multiple sources if possible.

7. The spec should allow some level of flexibility. For each product, you should specify a range of acceptance. For example, you may require USDA Choice whole beef tenderloins, but may accept products in both the $C$ arid $D$ size ranges. In some 
instances, you may have zero flexibility with the products you require, but those might cost you more.

In essence, the selection and procurement process should provide you the ability to maintain continuous supply at a minimum cost while maintaining desired quality levels. Above all, your purchasing activities should help you maintain your restaurant's competitive position in the marketplace.

Receiving and Storage: Receiving procedures are the other side of the specification coin. After you have properly identified and procured the products you need, you must maintain effective controls in how products are received and stored by your operation. The following are the six key elements of the receiving process:

1. Ensure that product quality, quantity, condition, and price are correct and as specified.

2. Expedite products into storage or move them to production.

3. Aid the purchasing department in evaluating a supplier's performance.

4. Check the performance of the purchasing department.

5. Serve as an accounting checkpoint.

6. Inform purchasing and production of shortages and returns.

Based on those six points, here is a specific approach to receiving. The receiving personnel should:

1. Verify the quantities of the items delivered. This involves reconciling your purchase order against the supplier's invoice, and against the products that are actually delivered.

2. Verify the quality and specifications of the items delivered to make sure that they match your product specifications. You'll generally want to reject products that don't meet specs.

3. Verify the price charged against the quoted price. Your vendors should deliver at the agreed upon price and that amount should appear on all paperwork, along with all discounts, specials, and returns or credits.

4. Initiate the processing of the invoice. Once you receive the products and ensure that you received what you ordered, submit the invoices for prompt payment, based on the terms and arrangements set up with your suppliers.

5. Inform production of any shortages. Whether the vendor doesn't have all the desired product or whether your receiving staff has rejected some foodstuffs, you'll need to 
make sure that the production team knows about shortages and can adjust production accordingly.

6. Transfer all product to appropriate locations. Once products are received, you need to ensure they are appropriately stored or put into production.

Storage: Your storage areas allow you to maintain a sufficient supply of foodstuffs, so that you have a buffer between purchasing and production. But the storage facilities must be appropriately secure, climate controlled, and large enough to meet your operation's needs. This particularly includes controlling both temperature and humidity for perishable products. At a minimum, your storage facilities should maintain the products in the proper condition until needed for production. Managing your inventory to prevent waste and spoilage is a key factor, even for products that improve in storage (e.g., wines and produce that need to ripen, such as avocados and bananas).

The purchasing process should take into account par stocks, of course, along with the shortterm and long-term needs of production. Your storage facilities must act as a staging area in the sense that everything can be easily found and retrieved. Products should be inventoried, labeled, and dated. Generally, you'll use the oldest stock 'each time, but there may be times when newer stock must be used. You need to use the ripest avocados, for instance, no matter when each case was delivered. As that example illustrates, you need to keep track of the quality and condition of all products in storage, with the goal of converting all your purchased items into revenue. We discuss this matter of ordering and storing foods in greater detail later in this chapter, in the context of inventory management.

Recipe Management: To ensure that your guests receive consistent products and that your costs are accurately reflected, you need to use well-tested, standardized recipes. Your tested, quantity recipes provide both 'a method (instructions for making a food dish) and the list of necessary ingredients, specified as the foods are found in inventory. But we want you to think of a recipe as more than a food-chemistry formula. Think of recipes as management tools. Properly developed recipes allow management to employ materials (ingredients), labor, and facilities and equipment in the most effective and efficient manner. A standardized recipe should contain:

- A summary of ingredients, listed in order of use

- The required quantities of each ingredient

- Specific procedures for measurement (weight or volume)

- Portion size

- Yield (anticipated number of portions)

- Equipment needed for portioning, preparing, holding, and serving 
- Any garnishing or finishing details

- Storing and serving instructions

A good recipe will provide consistency. If the recipe is properly designed, it can be executed at any time by anyone who has sufficient skill. If you have numerous cooks on different shifts and days of the week, your recipe should control for individual differences among the employees, produce a consistent taste and appearance, and produce the same cost and yield each time it is used.

Although good recipes cut down on the need for direct management supervision, they do not alleviate managers' responsibility to supervise and check production and service quality throughout the process. Recipes are really only the first step to ensure product consistency and quality and cost containment.

Product and Service Execution: By controlling product and service execution, your goal is to deliver consistent, quality products and service. This cannot be done without an understanding of your cost structure, supply chain' and production and service processes. All the elements discussed previously regarding cost of sales become meaningless without the necessary attention to detail to ensure that products are made and served correctly and consistently.

\section{Gross Margin}

So you bought the raw materials, cooked and served the dishes, and brought in revenue. If you subtract your cost of goods sold (COGS) from sales revenue, you'll have a figure called gross margin. From this, you still must cover your other prime cost of doing business-labor costs. In restaurants, the term prime cost is used to refer to the COGS (food and beverage) plus the cost of labor and benefits. Successful restaurants typically have prime costs in the range of 50 to 70 percent, leaving between 30 and 50 percent to cover all other operational expenses and profit. Those other expenses are controllable expenses, occupation expenses, and other ownership-related costs. The way these expenses are handled is a strong indication of how effectively a manager is running the business.

Controllable Expenses: Controllable expenses are those under management's direct control. Expenses can be classified as either fixed or variable. Fixed expenses show the same dollar amount for each period or sales volume. Common fixed expenses are rent, license fees, and administrative and general expenses. A variable expense tracks the volume of business, including cost of goods sold and direct operating expenses. Some expenses contain both a fixed and a variable component. Rent, for instance, may be a fixed dollar amount, plus a percentage of sales. Let's look at your controllable costs, starting with a big one-labor. 
Labor: The management of the labor function will make or break a restaurant. Most restaurants have two types of positions: managerial and supervisory (known in the United States as exempt employees under federal labor law), and line-level employees (known as nonexempt employees). Managers or supervisors, who are paid salaries and cannot earn overtime, are responsible for the overall functioning of the operation, while line-level employees, who are paid by the hour, are on the line doing the cooking, serving, and support functions related to guest service.

Scheduling is the key to controlling labor costs, and this is a challenging and complex job. Managers must schedule the right number of employees (managers and line-level) with the right skill level to match the level of business for the right amount of time or time period. (The complications of scheduling a seasonal ski operation, discussed in Chapter 10, are similar for restaurants.) A well-planned production schedule for kitchen staff and service schedule for the front of the house is crucial to optimizing your labor. To do this, you'll need a clear understanding of the business demands (i.e., forecast) so that you can adjust staffing by day parts, or days of the week depending on expected business levels. Labor is generally considered a fixed expense, since a particular level of staffing can cover a wide range in the number of meals served, and a certain level of staffing is needed just to open the doors.

Benefits: In addition to wages, you must pay for benefits, both mandated ones (Social Security, Medicare, unemployment, and disability insurance) and those given by your choice (medical and other insurance, meal allowance, uniform costs or a uniform allowance, day care or dependent care, and paid vacation or sick time). If you find yourself in a competitive labor market, a well-constructed benefits package may give you a hiring advantage.

- Direct Operating Expenses: There are many variable expenses directly associated with delivering service to guests, such as uniforms, laundry, china, glassware, menus, cleaning supplies, decorations, and kitchen fuel. Other typical expenses include the following:

- Music and entertainment: recorded or live music, licensing, or subscription fees;

- Administrative and general: usually fixed, consisting of items needed for the operation of the business, but not directly connected to serving guests, such as office supplies, postage, phone, and data processing costs;

- Marketing and advertising: the costs of promoting your restaurant, usually variable, such as mailers, coupons, comped meals, and any advertising;

- Repairs and maintenance: regular upkeep and repair; 
- Utilities: costs of fuel, water, waste removal, etc.;

- Franchise fees or corporate overhead: fees paid to a home office or franchisor;

- Occupation expenses: Expenses like rent, liquor licenses, property and liability insurance, and any payments for equipment rentals. A lease allows a restaurant operator to keep start-up costs low. In most cases a long-term lease [five years or longer] is beneficial for both parties to help control variation in revenue for the property owner and occupation expenses for the restaurant operator. However, some restaurant operators prefer to own the building and the land, to have greater control of their facility. In this case, the restaurant owner is responsible for all of the mortgage payments, and property taxes and fees associated with the building and land, instead of a rent payment. Occasionally, a restaurant operator will own the building but not the real estate. In this case, the owner of the building will pay rent for the land, and property taxes and fees for the value of the building;

- Depreciation: Operators are permitted to depreciate the assets they own over time, as a noncash expense against revenue, for tax purposes. The schedule of depreciation applied depends on the type of asset, but it generally reflects the concept that the value of certain already purchased assets diminishes over time;

- Interest: payments on debt or lines of credit;

- Other income or expenses: income and expenses related to the sale of auxiliary products, such as clothing, equipment, or package goods;

- Earnings before income tax (EBIT): After you subtract all the expenses described here from, your revenue what remains is your profit before income tax.

All of these revenues and expenses show how a restaurant functions. ${ }^{4}$ Let's now look at how you compile these figures (and other numbers) into a balance sheet, which is a critical management tool.

\section{Balance Sheet}

The balance sheet addresses what you own, what you owe, and who you are in business withat a given time. A balance sheet consists of assets, liabilities, and equity. By definition, your assets are equal to your liabilities plus equity. Let's look at the relationship of these three categories. 
Assets

Your assets will consist of both current and long-term holdings. Your current assets will consist of:

- Cash on hand: This is the money you have in the bank. You need sufficient cash to cover operating expenses. This can be a struggle for newer restaurants, which require greater amounts of cash to cover operations until they have sufficient cash flow. This often takes up to a year to establish. Your operations should generate a certain amount of cash, and under normal circumstances you should realize a steady, reliable cash flow from operations so that you don't have to rely on outside cash, such as a line of credit.

- Investment instruments: Good as it is to have, cash is a nonproductive asset. Thus, you can use short-term, liquid savings instruments (e.g., certificates of deposit, money market) to ensure that your cash is not idle, but is readily available. (We know interest rates are low, but it's still better than stuffing your cash in a mattress.)

- Accounts receivable: This money is owed to you in the normal course of business. The trick is to keep receivables as current as possible, ensuring that guests, vendors, or other partners pay promptly. These accounts are short term and should turn over quickly.

- Inventory: This describes the products that you have purchased, but have not yet placed in production. As products are transferred into production from inventory, the cost of the asset moves from the balance sheet inventory line to the cost of goods sold area on the income statement. The balance sheet provides a good reminder that excessive inventory is an unneeded expense that can lead to waste and pilferage, if not properly managed.

In that regard, inventory turnover is an important indicator as to how well your restaurant is using its resources. Inventory turnover rate is calculated by dividing total inventory (per year) by the average inventory. Generally, the higher the inventory turnover rate, the better, although the actual rate depends on your concept. A quick service restaurant's inventory turnover rate, for instance, can be as high as 100 (turned over every 3.65 days), but a table-service restaurant will have much lower inventory turnover rates. Other assets you hold are considered long term and do not turn over often, if at all. We take a more detailed look at inventory management in the accompanying sidebar. 


\section{EOQ: A Scientific Approach to Inventory Management}

Few tasks are more important than making sure the inventory is managed correctly, because inventory means dollars invested in goods, some of them highly perishable. Keeping track of inventory requires taking a regular physical inventory (at least monthly or quarterly). Too often, this is left: to a junior staff member. Although you always need sufficient, highquality stock, the less money tied up in inventory, the lower your operating costs. Because of the importance of inventory management, we suggest an approach called economic order quantity (EOQ).

Let's take a look at how much money can be tied up in inventory. The turnover rate is total inventory (per year) divided by the average inventory, which is calculated by adding inventory at the beginning of the period (say, the first of the month) and the inventory at the end, and dividing it by two [(Beginning Inventory + Ending Inventory) / 2]. Thus, if your restaurant generates $\$ 3$ million in annual revenue, and you have a COGS of 28 percent, you're buying about $\$ 840,000$ worth of goods each year. If you have a table-service restaurant with an inventory turnover rate of 35 , you have about $\$ 24,000$ tied up in inventory at all times. Increasing your inventory turnover rate not only reduces money tied up in your operations, but also decreases the space you need for storage and the chance that products will spoil or be pilfered. If a restaurant fails to forecast its anticipated business volume, managers will be forced to do a lot of expensive last minute ordering. Or, worse, the restaurant runs out of inventory, resulting in lost sales opportunities and disappointed guests.

\section{Economic Order Quantity}

One effective purchasing approach is to use EOQ to strike an appropriate balance between order frequency and the cost of keeping inventory on hand. Say that you are operating a pizza restaurant that uses large quantities of tomato sauce. Each time you place an order for a shipment of this sauce, your restaurant incurs the usual expenses connected with ordering and receiving. Placing fewer orders lowers those expenses, but a large order will increase your inventory costs. So, here's how to strike the balance between too few or too many orders.

A simple calculation and table will help you determine the optimum number of cases to order. Let's use the numbers given below, as an example. 
Annual Usage $(U)=500$ cases (to be ordered in increments of 10 cases)

Case Cost $(C)=\$ 96$

Acquisition Cost $(A)=\$ 25$

Annual Inventory Carrying Costs $(\mathrm{I})=12 \%$

Inventory Carrying Costs (ICC) $=(10 \times \$ 96 \times 0.12) / 2=\$ 57.60$

Acquisition Cost $=50 \times \$ 25=\$ 1,250$

Total Cost: $\$ 1,250+\$ 57.60=\$ 1,307.60$

As you can see from the "total cost" cells in Table 16.1, the optimal, or EOQ, lies between 40 and 60 cases. Below 40 and above 60, the total costs increase rapidly. Instead of calculating acquisition cost and inventory carrying cost for each increment, you can use the following formula for EOQ. Note: In Table 16.1 to calculate the ICC, you use 2 in the denominator to approximate the average inventory which would be beginning inventory less ending inventory divided by 2 .

Table 16.1

Hypothetical Cost of Ordering and Inventory for Tomato Sauce

\begin{tabular}{ccrr}
\hline Order Quantity & Acquisition Cost & ICC & Total Cost \\
\hline 10 & $\$ 1,250.00$ & $\$ 57.60$ & $\$ 1,307.60$ \\
20 & $\$ 625.00$ & $\$ 115.20$ & $\$ 740.20$ \\
30 & $\$ 416.67$ & $\$ 172.80$ & $\$ 589.47$ \\
40 & $\$ 312.50$ & $\$ 230.40$ & $\$ 542.90$ \\
50 & $\$ 250.00$ & $\$ 288.00$ & $\$ 538.00$ \\
60 & $\$ 208.33$ & $\$ 345.60$ & $\$ 553.93$ \\
70 & $\$ 178.57$ & $\$ 403.20$ & $\$ 581.77$ \\
80 & $\$ 156.25$ & $\$ 460.80$ & $\$ 617.05$ \\
90 & $\$ 138.89$ & $\$ 518.40$ & $\$ 657.29$ \\
100 & $\$ 125.00$ & $\$ 576.00$ & $\$ 701.00$ \\
\hline
\end{tabular}

The sample EOQ graph in Figure 16.1 shows the decrease in ordering cost as the order size increases and, at the same time, shows how inventory carrying costs increase as order size increases. 
Figure 16.1

Sample EOQ Graph

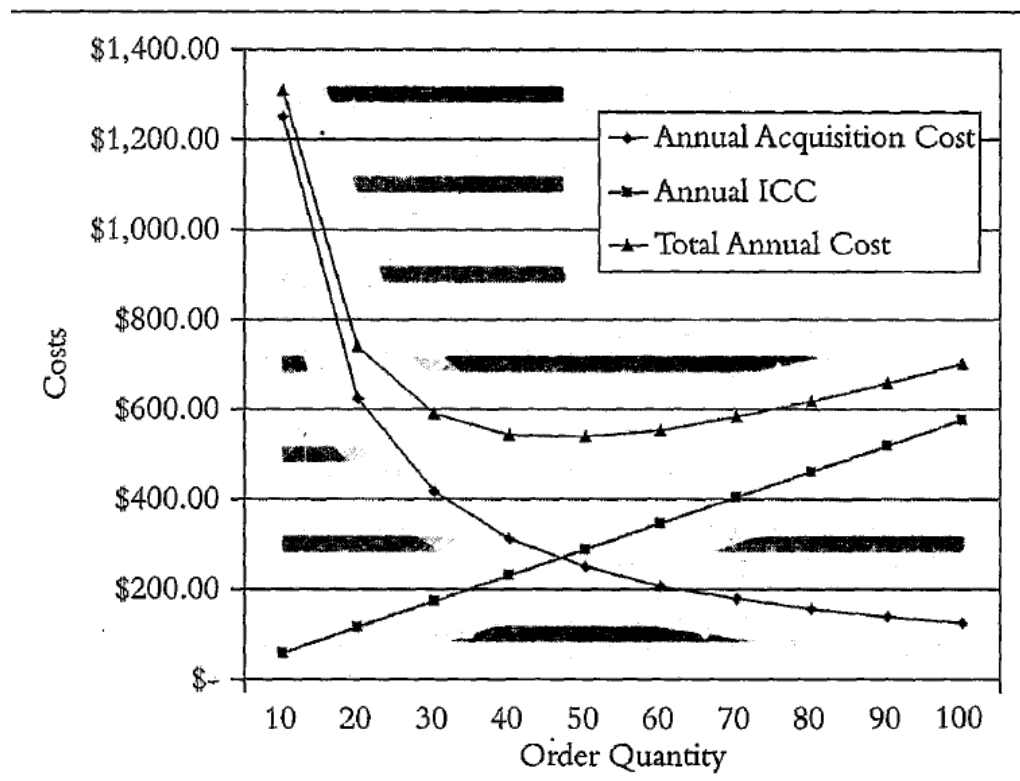

Although this EOQ example demonstrates the financial effects of inventory and ordering management, we must note that the EOQ approach has its limitations. For example, we assume that ordered items are shelf stable and that demand is relatively level. Furthermore, we assume little or no price fluctuation, sufficient storage space, and enough capital to buy in large quantities. The EOQ concept demonstrates the delicate balance between the cost of too much inventory and the expense of ordering too frequently.

- Investments in subsidiary companies: Sometimes operators own shares in other businesses or subsidiaries. The book value of these shares is treated as an asset, for which gains are realized only when sold.

- Building and equipment: Finally, any equipment, furniture and fixtures, owned buildings and land, and leased assets are recorded on the balance sheet at book value. Some assets are depreciated, which will affect their value upon replacement.

\section{Liabilities}

Your liabilities will consist of both current and long-term debt. Your current liabilities will consist of:

- Accounts payable: obligations to the people with whom you do business. 
- Notes payable and other credit: formal debt obligation that you have undertaken, like a short-term line or credit, a mortgage, or a lease.

\section{A Final Note on Financial Statements}

We've presented detailed discussions about the income statement and balance sheet to show how the functioning of a restaurant is documented and recorded. The balance sheet also has an equity section that outlines the ownership characteristics of a business.

Creating and serving great food and beverages is the start to a successful business, but without a solid grasp of the financial implications of all elements in a restaurant, it is unlikely that you will succeed. Let's examine how to use your understanding of your business to be a viable competitor in your market.

\section{A Restaurant Dream}

Say that you just received a call from a commercial real estate agent offering you a site that might bring you closer to your dream of opening a restaurant. But you have to work out the finances. The rent alone is $\$ 24,000$ per month. You will also have to pay for insurance, taxes, and trash removal, amounting to another $\$ 3,000$ per month. Approximately 3,500 square feet of the space can be used for food production (the kitchen and back of the house), the seating area, and the take-out window. Another 1,000 square feet can be dedicated to storage, office space, and other support functions.

So, let's do a quick estimation to help you to assess the feasibility of your restaurant dream. Industry standards suggest that prime restaurant locations dedicate approximately 12 percent of total sales revenues toward rent (including property taxes, insurance, and trash removal). Good locations require about 10 percent of revenue, and standard locations about 8 percent.

You judge that your potential restaurant site is good but not prime, because it's at a busy intersection in a college town. Thus, you assume that dedicating 10 percent of total revenue toward rent seems justified. On that basis, you know that you need to generate about $\$ 3,250,000$ per year in total revenue to make your restaurant economically feasible (i.e., to cover all of your expenses and still make some fair profit). 
Scanning the current competition, a rough calculation puts the average check (lunch and dinner combined) at $\$ 12$. For ease of calculation you are assuming daily operating hours are from 11:00 AM to 11:00 PM. This means that you need to sell 270,000 meals per year, or about 740 per day. This would require a steady stream of 61 patrons per hour, or about one per minute, on average. You now have to decide if this is realistic.

Although hungry students like to eat out a lot, you must factor in semester breaks. In a true college town, summer business drops off significantly and dies entirely during the winter break. When all those students leave town, you are mostly depending on college professors (a notoriously thrifty bunch) and university staff (not highly paid). This means that you have roughly nine months of the year-perhaps 40 weeks at most-to generate all the revenue to make this restaurant successful. Based on these serious doubts, you wisely tell your real estate agent you are putting your restaurant dream on ice until you find a less expensive location.

Just as a closing note, this scenario is not entirely invented. Sadly, we have seen would-be restaurateurs take this plunge without doing the math. The result has been the failure of numerous delightful restaurant concepts.

\section{How is my Operation Doing?}

Now that you have looked at a restaurant's financial aspects, let's look at the key question of how your operation is doing. The first response to this question is: "Compared to what?"

So, you understand how your business operates, you have the data properly recorded, and you understand what it means. The next step is to compare your performance over time, from day to day, week to week, month to month, and year to year. But that is not enough. You also need to be able to benchmark your performance against both direct and indirect competitors. Direct competitors are restaurants similar to yours, say, Applebee's, TGI Friday's, and Chili's, if you're running a midrange casual-dining restaurant. Although each has a distinct concept, many guests might consider them to be interchangeable, since their price points are similar. Likewise, customers might view quick-service operators Wendy's, McDonald's, and Burger King as relatively interchangeable. Even fine-dining steakhouses have direct competitors who are similar. Direct competition is relatively straightforward, and operators actively compete for market share with their direct competition. Operators who do a better job delivering on the food, service, and environment will reap the rewards of a loyal, growing guest base. 
Indirect competition is any business that provides consumers with an alternative to dining at your restaurant. The basic premise of indirect competition is that if you are not eating in my restaurant, you are eating somewhere else. Thus, determining competitors is complicated. For mid-scale casual operators, that "somewhere" could be a grocery store that offers prepared foods or an eating area, a fine dining or upscale casual restaurant, or a quick service or fast casual restaurant. Those are just the alternatives for food away from home, since your potential guests could decide to fire up the grill and eat at home. Since you can't do much about indirect competition, your best plan is to be the best among your direct competitors and hope that your offerings are special enough to grab meals from your indirect competition occasionally.

In conclusion, to succeed you need to understand your operation, your guests, and your marketplace. In addition to being in tune with your immediate surroundings, you should also take advantage of industry data that are available to you. Each year the National Restaurant Association, in conjunction with consulting firm Deloitte, publishes the annual Restaurant Industry Operations Report. This report contains data that summarize the state of the restaurant industry and provides an analysis of restaurants in the limited and full-service domains separated by check average. This benchmark data offers additional insight to help you better understand how you are doing. Note carefully that the focus is on the numbers.

\footnotetext{
${ }^{1}$ H. G. Parsa, J. T. Self; D. Njite, and T. King, "Why Restaurants Fail," Cornell Hotel and Restaurant Administration Quarterly 46(3) (2005): 304-322.

${ }^{2}$ National Restaurant Association and Deloitte \& Touche, Uniform Systems of Accounts, 7th revised ed. (Washington, DC: National Restaurant Association, 1996).

${ }^{3}$ Adapted from J. Ninemeier, Planning and Control for Food and Beverage Operations, 3rd ed. (East Lansing, MI: Educational Institute of the American Hotel and Motel Association, 1995), 132.

${ }^{4}$ See National Restaurant Association and Deloitte, "Restaurant Industry Operations I Report: 2010 Edition," http://www.restaurant.org/esdpdf/OpsReport2010.pdf. (accessed February 7, 2011).
} 